\section{Família, subjetividade e linguagem: gramáticas da criança "anormal"}

\author{
Family, subjectivity and language: \\ the "abnormal" child grammar
}

1 CLAVES - Centro Latino-Americano de Estudos da Violência e Saúde Jorge Careli, Escola Nacional de Saúde Pública,

Fundação Oswaldo Cruz Av. Brasil, 4.036 sala 702 Manguinhos 21040-361, Rio de Janeiro, RJ, Brasil. cavalcan@ensp.fiocruz.br

\begin{abstract}
This paper discuss how the birth of an "abnormal" child causes a social impact in the family's life. In order to articulate the individual and the social levels, it was integrated some conceptual notions from antrophology and philosophy of language. This study is based upon an empirical data of life histories from "abnormal" children's families, which was collected in a research made in Rio de Janeiro. In these analyses, it is done some descriptions of families' reactions when they find out about their children's mental illness. It is also given an emphasis in the families' capabilities to communicate their own experience against the $a b$ normality, as a learning way of gaining strength and wisdom. The conclusions say that the procedure to communicate the diagnosis is very important, because it changes the child condition to an "abnormal" one, and it also creates a new kind of mother, and a new kind of father. A lot of pain will have to be faced. It is necessary to comfort the families and to give them the right orientations. Families' routines will be changed. A new kind of care will be developed with these children; new responsibilities and some sacrifice's acts will be expected from their families. It is needed a new repertory of knowledge. It is very important to offer family support in order to help them to overcome desperation, confusion, and disorientation. But, what it is more difficulty than anything is the fight against the social discrimination, which injures people inside and outside.
\end{abstract}

Key words Family, Subjectivity and language, Abnormal child, Child mental illness
Resumo O artigo procura refletir sobre o impacto do nascimento social de uma criança "anormal" na família. Propõe uma grade conceitual, abstraída da antropologia e da filosofia da linguagem, que permita articular sujeito e contexto social. Analisa um rico material empírico, baseado em histórias de vida de famílias com filhos excepcionais, de uma pesquisa desenvolvida no município do Rio de Janeiro. Faz uma descrição densa das etapas iniciais, pelas quais a família passa, quando descobre a anormalidade mental de seu filho, na primeira infância. Este enfoque valoriza a capacidade das famílias de comunicarem sua experiência de enfrentamento da anormalidade, como aprendizado, luta e sabedoria de vida. As conclusões revelam que o momento do diagnóstico é delicadíssimo, pois transforma o ser da criança e inaugura um novo pai e uma nova mãe. As reações à dor serão inevitáveis. Um acolhimento e uma orientação clara são fundamentais. A rotina familiar se altera. Uma ética da responsabilidade e do sacrifício se impõe pelos cuidados ao filho. A família precisa desenvolver um novo estoque de conhecimento. O apoio familiar é crucial, para que a família tenha condições de fazer face ao desespero, à confusão, à desorientação. O combate mais difícil é contra a discriminação social porque traz, como conseqüência, uma dor que fere por dentro e por fora.

Palavras-chave Família, Linguagem e subjetividade, Criança anormal, Doença mental infantil 


\section{Introdução}

Para constituir um modo de pensar sobre a subjetividade e sobre a linguagem que não se limite a uma compreensão meramente psicológica, irei desenvolver dois momentos reflexivos complementares. Primeiro, vou buscar na antropologia e na filosofia da linguagem uma grade conceitual que permita articular sujeito e contexto social. Segundo, vou fazer uma análise etnográfica baseada em histórias de vi$d a$, esculpindo as subjetividades do cenário sociocultural que as produziram. A escolha desta metodologia se deve à necessidade de se compreender, do ponto de vista sócio-histórico, o impacto do nascimento social de uma criança "anormal” na família.

O nascimento de uma criança "anormal" é um desses acontecimentos inesperados que põe à prova cada um de nós, pais, mães, irmãos, avós, tios, amigos, professores, profissionais da saúde, pesquisadores, gestores da saúde e da educação. Convida-nos a buscar soluções e a entender que o desafio é de todos. No entanto, a família é o primeiro núcleo social a ser intensamente "perturbado" por ele, o primeiro a buscar respostas nos diversos setores da sociedade e o último a lidar com as conseqüências para toda a vida. Por isso, eu me debruçarei sobre o que as famílias têm a dizer. Farei uma descrição densa dos primeiros momentos de descoberta da anormalidade mental infantil. Acredito que nossos saberes sejam muito "débeis" para compreender, do ponto de vista de quem vive, o desafio hercúleo de se enfrentar uma anormalidade em nossa sociedade, por demais individualista e hostil às diferenças.

Tomo como base a pesquisa "A gramática da criança 'anormal' na narrativa familiar: um estudo etnográfico” (Cavalcante, 1996) que reuniu um rico material empírico sobre essa situação na cidade do Rio de Janeiro. Retomo esse estudo principalmente para ampliar sua análise. Esclareço que o uso da categoria "anormal" se deve : 1) à tentativa de "escapar" às terminologias usuais e demarcar o olhar etnográfico; 2) à escolha de uma categoria relevante à etnologia; 3 ) ao modo como essas crianças são vistas no senso comum, como aquelas que "não são normais", portanto "anormais".

No presente estudo, a categoria "anormal" se refere aos casos descritos a seguir.

1) Deficiência mental-funcionamento intelectual bem inferior à média, com prejuízos no funcionamento adaptativo atual nas seguintes áreas: comunicação, cuidados pessoais, vida doméstica, habilidades sociais, independência, entre outras (DSM-IV, 1995).

2) Autismo - os chamados transtornos invasivos do desenvolvimento (DSM-IV, 1995). A palavra vem do grego autos que significa si mesmo, referindo-se a alguém retraído e absorto em si mesmo. Alguém que caminha como que envolto em sombras, vive em um mundo próprio ao qual não podemos chegar. Autismo é o mais grave distúrbio da comunicação humana que compromete a socialização e a imaginação (AMA/SP, 2000). Observa-se, nesse quadro, isolamento extremo do indivíduo, desapego do ambiente, boa potencialidade intelectual (Ajuriaguerra, 1980).

3) Psicose infantil - problema da personalidade relacionado a um transtorno ocorrido na organização do ego e intimamente ligado à relação da criança com o meio ambiente. Comportamento inadequado face à realidade; investimentos insuficientes ou exagerados no campo cognitivo, afetivo e da atividade, ocasionando comportamentos rígidos ou inconsistentes; vida imaginária pobre; relação inadequada com os outros (Ajuriaguerra, 1980).

Ao invés de um saber distante, aprisionado ao olhar da doença, procuro dialogar com o objeto de reflexão, valorizando a capacidade das famílias de comunicarem sua experiência de enfrentamento da anormalidade como aprendizado, luta e sabedoria de vida. Cada família é uma unidade cooperativa que compartilha expectativas e interesses complementares. Nesse acontecimento inesperado, a família é desafiada em seus laços de afeição e na solidariedade de sentimentos que mantém. Marcada por diferenças de gênero, geração, classe social, entre outras, a família se vê às voltas com o difícil desafio de socializar uma criança diferente, como veremos adiante (Linton, 1987).

\section{Esculpindo a subjetividade na linguagem: a gramática do significar}

Neste momento, me proponho a articular ferramentas teóricas que auxiliem a pensar a interface entre subjetividade e linguagem, formando uma grade conceitual para a análise de dados que se dará a seguir. Pensar a subjetividade ou as produções de subjetividade que temos forjado, neste homem recém-inventado 
(Foucaut, 1995), exige um cuidado redobrado. Um olhar que se debruça sobre os "cacoetes" do nosso pensar e do nosso saber.

O modo como olho para alguém, aquilo que vejo, o que escuto, o que penso e o que falo acerca dessa pessoa vai trazer conseqüências para a compreensão que tenho dela. Pretendo estudar o indivíduo não como uma "coisa em si”, natural, passível de ser desvendada. Longe de pensá-lo como essência, vejo-o como objeto inacabado, em construção, produto de suas condições e contradições históricas (Foucault,1995). Usarei um caminho do pensamento que favoreça a compreensão, como o faz o chamado pós-estruturalismo, que se distancia de noções tais como forma, sistema, estrutura, trazendo mudanças epistemológicas no campo da linguagem, da filosofia e das ciências. Essa nova tendência oferece, a meu ver, ferramentas para revisão do modo individualista e unidimensional de se ver a subjetividade, redescrevendo-a em termos de pensamento complexo e permeável a outros conhecimentos, como sugeriu Santos (1997).

Primeiramente, vou buscar na antropologia ferramentas para esculpir a subjetividade sem esvaziá-la de seus atributos contextuais. Introduzo a idéia de "descrição densa" em contraste com a idéia de "descrição superficial", noção de Ryle, utilizada por Geertz (1989) para definir o campo da etnografia. A descrição superficial aproxima-se da descrição de um fenômeno propriamente dito, como por exemplo, piscar o olho. A descrição densa diz respeito à intencionalidade que acompanhou o gesto: piscar porque entrou cisco no olho, ou piscar para imitar alguém com um tique nervoso (...) A etnografia é uma descrição densa, na medida em que o que o etnógrafo enfrenta, de fato, é uma multiplicidade de estruturas conceituais complexas, muitas delas sobrepostas ou amarradas umas às outras, que ele tem que, de alguma forma, primeiro apreender e depois apresen$\operatorname{tar}$ (Geertz, 1989).

O olhar etnográfico não procura, contudo, captar os fatos como se pudesse obter uma máscara dos dados observados. Ele pretende esclarecer o que ocorre, reduzindo a perplexidade do desconhecimento. Um ritual, um costume, uma idéia ou um acontecimento deixa sempre algo insinuado como informação de fundo. Quaisquer que sejam os sistemas simbólicos, é possível ter acesso empírico a eles, por meio da observação. No entanto, não se pode estudar deuses ignorando suas imagens; ri- tos, sem analisar os objetos e as substâncias que fabrica ou que manipula o oficiante; regras sociais, independentemente das coisas que lhes correspondem (Lévi-Strauss,1990). A análise antropológica não pode ser dissociada do acontecimento, do lugar, da ocasião ou das pessoas nas quais o estudo se baseou. Qualquer generalização que se possa fazer nesse tipo de interpretação se deve muito mais à delicadeza das descrições do que à amplidão das abstrações. A antropologia oferece uma alternativa de pensamento complexo na medida que estuda o indivíduo ou a pessoa em seu contexto histórico-cultural, articulando símbolo e signo. Nela o conhecimento se dá na intersubjetividade do jogo social.

Em Wittgenstein (1979), no segundo período de sua obra, encontro uma caixa de ferramentas, sobre o estudo da linguagem, que me permite "escutar" o homem nos moldes de um pensamento complexo. Para ele, as palavras são como ferramentas de diferentes funções e o que as diferencia é o uso que fazemos delas. $\mathrm{O}$ autor distingue a "gramática superficial", aquela que corresponde à doutrina da construção frasal correta, da "gramática profunda", aquela que vê as diferentes espécies de emprego de frases (...), os diversos modos das frases que aparecem. Um mesmo radical de frase pode estar associado a diversos modos ou atos dos discursos (Stegmüller, 1977). Para Wittgenstein, os inúmeros atos dos discursos (palavras e proposições) são operados à semelhança de um jogo de xadrez. Entendemos os significados das palavras se conhecemos as "regras do jogo". Cada uso diferente de palavras corresponde a um jogo de linguagem diferente (Faustino, 1995). Seu estudo, contudo, não privilegia a idéia de representação mental, enfoque que se baseia na relação entre significado $e$ objeto, ou seja, naquilo que "cola" as palavras às coisas que elas representam. Ao invés disso, ele privilegia a relação existente entre significado e uso. A palavra adquire sua significação em seu uso contextual. Por esta razão, a gramática do significar não se confunde com a gramática do representar. Wittgenstein substitui a pergunta: o que é o significado de uma palavra, pela pergunta: o que é uma explicação do significado de uma palavra. Isso traria a vantagem de afastar a tentação de procurar o significado oculto das coisas (Faustino, 1995).

A análise wittgensteiniana da linguagem não procura descobrir o pensamento que subjaz atrás do signo, desvendar o simbolismo 
oculto, e nem desentranhar algum tipo de intenção imperceptível. Ela focaliza as regras que estão implicadas na produção, reprodução ou invenção de significados (...), na exteriorização de modelos de ação e dos padrões de comportamento (...), no inter-subjetivamente compreensível (Faustino, 1995). A gramática do significar interroga o que são as significações, exibe a riqueza das possibilidades de uso da linguagem, realça a diferença, a variedade, a multiplicidade de explicações dos significados. A compreensão wittgensteiniana da linguagem é demolidora de uma visão essencialista e mentalista, na medida em que devolve à comunicação pragmática das pessoas, o poder de construir significados. Que implicações esse pensamento tem para se analisar uma teoria do sujeito? Ele se distancia da idéia de essência e da idéia de mente, como depositárias de representações. O que se privilegia nesse enfoque, não é o que está na cabeça da pessoa, mas aquilo que sai da sua boca, ou seja, o que é dito no uso da linguagem.

Ganha destaque o dizer e o dito, ou seja, o que foi dito, como foi dito e o contexto de enunciação em que a fala se deu, contexto aqui entendido como o ambiente em que se produziu o discurso. Isto é, os diferentes modos de enunciação das palavras produzem diferentes efeitos de sentido. Uma palavra não é o sentido que ela toma num contexto, (...) enunciado não é a soma das significações, mesmo contextuais, das palavras. O efeito de sentido contextual de uma palavra é somente a mudança produzida neste contexto pela introdução desta palavra, isto é, a modificação pela qual a palavra é responsável no sentido global do enunciado (Ducrot, 1987). Isso amplia a idéia de contexto lingüístico para além do ambiente de uma palavra numa frase, incluindo os fenômenos sociopsicológicos que aparecem no ato de enunciação. Não é apenas o enunciado que conta, mas sobretudo $o$ ato de enunciação.

Ducrot (1987) descreve a língua como um espaço de confronto de subjetividades, um território mediado pela polêmica. Qualquer frase que se diga implica a exclusão de alguma coisa, qualquer coisa que se diga são muitos sujeitos falantes. Quando uma mensagem é transmitida, ela produz um efeito de sentido, como resultado de um jogo de sentidos produzido pelo emissor, que será reinterpretado pelo destinatário. O enunciado cria juridicamente uma situação nova, uma atribuição de poder que pode ou não produzir o efeito esperado.
A noção de subjetividade foi introduzida no estudo da linguagem por Benveniste. Para o autor, é na linguagem e pela linguagem que o homem se constitui como sujeito; porque só a linguagem fundamenta na realidade, na sua realidade que é a do ser, o conceito de "ego". A consciência de si mesmo só é possível se experimentada por contraste. Eu não emprego eu a não ser dirigindo-me a alguém, que será na minha alocução um tu. Essa condição de diálogo é que é constitutiva da pessoa, pois implica reciprocidade - que eu me torne tu na alocução daquele que por sua vez se designa por eu (Benveniste, 1974).

Toda fala entrelaça vozes de diferentes instâncias sociais, reproduzindo uma espécie de agenda moral. Signo e situação social estão indissoluvelmente ligados (...) A palavra é o signo ideológico por excelência; ela registra as menores variações das relações sociais (...) que se exprime na vida corrente (Bakhtin, 1979). Os contextos de enunciação variam e se mantêm tensos, em conflito o tempo todo, dialeticamente relacionados mediante uma coexistência conflituosa. Isso deve ser levado em conta na interpretação de contextos diferentes, no sentido de se considerar como um contexto de fala afeta o outro e qual o efeito de sentido do cruzamento de muitos contextos. O dialogismo de Bakhtin, o jogo de múltiplas vozes, remete à noção de jogo de palavras. Em resumo, a língua é vista como o cenário de um jogo de palavras, um território de confronto entre subjetividades, o embate polifônico de diferentes instâncias sociais, a coexistência conflituosa de vozes e efeitos de sentido.

Em sintonia com esses autores e idéias da filosofia da linguagem, Costa (1994) nos apresenta uma concepção de sujeito, desenvolvida por Rorty (1994), na qual o sujeito não é preexistente aos elementos lingüísticos constitutivos de sua descrição. O sujeito, o eu, o 'self' são um efeito da linguagem. Dizer que o sujeito é um efeito da linguagem é dizer que aprendemos a falar do sujeito sem necessitar de outro referente, exceto as palavras ou proposições que o definem. O sujeito, então, é o conjunto de enunciados, atitudes, estados, condutas ou processos intencionais formados por termos lingüísticos elementares como sensações, sentimentos, emoções, pensamentos, expectativas etc. (...) O sujeito é uma rede de crenças e desejos (...) Crenças são regras de ação seguidas conforme a tradição ou inventadas conforme os contextos de vida (...) Crenças e desejos são, portanto, realidades lingüísticas. 
O sujeito, para Costa, não se situa dentro de uma concepção estruturalista, na qual ficaria implicado na busca do verdadeiro sentido histórico de um evento inconsciente, do verdadeiro sujeito estruturado como uma linguagem que corresponde ao ideal cognitivo chamado por Rorty de "ideal da autopurificação". O sujeito deve ser situado no "ideal do auto-enriquecimento", que nos afasta da idéia de que tudo podemos conhecer. Tal ideal pode ser formulado na máxima pragmática que diz: não pergunte o que realmente sou; qual o meu verdadeiro eu. Pergunte como posso redescrever-me, de maneira a viver uma vida melhor e mais bela (Costa, 1994). Afastando-se da idéia do "conheça-te a ti mesmo", essa concepção situa o sujeito sem a idéia de "sujeito verdadeiro". Não há o verdadeiro, na medida em que o sujeito poderá ser descrito de tantas maneiras quanto o seu sistema de crenças puder dar sentido. Para conhecer o sujeito, diz o autor, precisamos de acordo, apenas, quanto ao julgamento de seu valor pragmático.

\section{Inquietações e cuidados metodológicos no estudo da narrativa familiar}

As reflexões feitas anteriormente tiveram como objetivo fornecer ferramentas para se pensar a interface entre subjetividade e linguagem. Cabe-me agora aplicá-las a uma pesquisa concreta e ao conjunto de preocupações que me acompanham como pesquisadora.

Comecei a duvidar de minha "escuta", enquanto trabalhava como terapeuta de família, ao ouvir histórias de pais e mães de crianças e adolescentes portadores de deficiências ou distúrbios mentais. Passei a ter a sensação de que apesar de tudo o que me falavam, sobre sua experiência com um filho "anormal", eu não conseguia efetivamente "ouvi-los". Não se tratava de um problema de audição, nem tampouco da falta de esquemas conceituais para que eu entendesse a família. A psicologia dispõe de vários recursos teóricos para a compreensão das famílias, na terapia familiar psicanalítica, na terapia familiar sistêmica etc. Eu não sentia falta de uma escuta psicológica, de um entendimento psicodinâmico. Eu sentia falta de ferramentas sociais também para poder olhar e escutar as famílias como pessoas totais, que enfrentam um desafio de conseqüências psicossociais bem complexas, para o resto de suas vidas, na maioria das vezes. Como ver essas fa- mílias articuladas em sua vida social? Como entender o papel da cultura familiar e social na constituição do psiquismo do grupo familiar? Como compreender o efeito de sentido do filho "anormal" no contexto enunciativo da família? Senti que deveria recorrer a outros paradigmas de pensamento e enriquecer o olhar Psi (jargão da área), para responder a essas questões, com maior profundidade. Para isso, busquei a perspectiva das ciências sociais, da antropologia e da filosofia da linguagem.

Em 1996, fiz uma análise etnográfica de narrativas de famílias com filhos (crianças e adolescentes) portadores de distúrbios mentais graves desde a primeira infância: deficiência mental, autismo, psicose infantil. Foram feitas 14 entrevistas individuais ( 7 histórias de vida e 7 estudos de caso clínico) e o registro etnográfico de atividades grupais com 45 participantes (15 de dois grupos terapêuticos que funcionaram por um ano; e 30 de duas atividades grupais sem fins terapêuticos). A pesquisa foi feita em duas instituições psicopedagógicas do município do Rio de Janeiro, uma pública e outra privada. Minha idéia, no momento, não é reproduzir a análise, previamente feita, em dissertação de mestrado (Cavalcante, 1996). Pretendo ampliar a análise anterior, a partir do quadro conceitual aqui desenvolvido.

Formulo a análise etnográfica das narrativas, que farei adiante, num enfoque pós-estruturalista. Vimos, anteriormente, que o sujeito e a vida social são eventos centrados no discurso. O discurso, por sua vez, é uma dramaturgia de vozes, uma fala viva, de onde extraímos o sujeito e o cenário social a ele associado. Estudos narrativos são meios para apreendermos algo sobre como as pessoas constróem o que sabem, sonham, como relembram o passado e como descrevem entre si o que ocorreu. Portanto, mais do que focalizar tópicos ou temas, extraídos das histórias, nós podemos apreender o modo como as pessoas pensam suas vidas (Basso, 1990). A história é um elemento de inteligibilidade social. A vida vai sintetizando eventos narrativos com uma base ética e moral. As emoções e o senso de coerência do eu podem ser conhecidos como uma subjetividade socializada (Gergen, 1994).

No entanto, é preciso ter cuidado para não se tratar a história como se fosse um relato coerente, um caminho, uma travessia, com "intenção", "projeto original", ordenação lógica e noção de começo, meio e fim. O real é descontínuo, formado de elementos justapostos, sem 
razão, cheio de imprevistos. Por outro lado, numa entrevista oral, o eu costuma fazer uma apresentação oficial de si, uma apresentação pública, submetida a coações e censuras específicas. Nesse sentido, é bom relembrar Bourdieu, quando diz que se deve atentar para o fato de que a representação mais ou menos consciente que o investigado fará da situação da investigação irá orientar todo o seu esforço de apresentação de si, de produção de si, numa espécie de ilusão biográfica (Bourdieu, 1996).

\section{Gramáticas do significar: o nascimento social de uma criança "anormal"}

Podemos dizer que um bebê, ao nascer, desafia os estoques de conhecimento do continente familiar que o recebe. E o que vem a ser isso? Cada família possui um repertório de experiências e situações vivenciadas que lhe serve de referência para interpretar o mundo e balizar suas ações (Schutz, 1971). Esse conhecimento forma uma tessitura psíquica, social e cultural que irá ancorar a chegada do bebê. É através desse estoque, construído na sucessão de gerações, que a família irá dar à criança as chaves de acesso ao mundo. Mas esse processo, habitualmente complexo, pode se transformar num desafio muito maior, em circunstâncias especiais. O nascimento de um bebê "anormal" ou o surgimento de distúrbios mentais na primeira infância produz uma perturbação que afeta toda a família. Distúrbios assim, tão precoces, interferem globalmente no desenvolvimento da criança. A família se vê em perigo, uma vez que seus recursos tradicionais serão insuficientes para fazer face à anormalidade. Um novo repertório deverá ser construído. Vejamos como isso ocorre, na narrativa das famílias.

Foi difícil ouvir do médico, pela primeira vez, que minha filha tinha uma deficiência, diz um casal. Sua filha foi diagnosticada como portadora de deficiência mental e deformações físicas. Desse dia em diante, o casal se viu frente a um "enigma”. A vida se tornou um objeto de interrogação, onde o que parecia ser o chão do cotidiano foge do campo de compreensão. Foram tantos os especialistas a opinarem, tantas orientações diferentes que as tomadas de decisões não deixaram de ser árduas e penosas. Muitos tratamentos, poucas respostas. Outro pai descreveu o momento de sua descoberta da doença do filho, deficiência men- tal, dizendo que ele se sentiu como um carro que sai fora da estrada. O momento do diagnóstico produz um corte muitíssimo doloroso, marcado por um grande choque e uma profunda sensação de desorientação. Um carro só sai fora da estrada se estiver desorientado, ou no caso de uma colisão com outro veículo, em face de uma forte pancada. A notícia de uma "anormalidade", nos primeiros momentos, soa como uma pancada, um acidente, um baque, um choque de grande proporção, que fere e que machuca.

A psicóloga Silva (2000) fala que o momento do diagnóstico tem a aparência de um machado que cai sobre a cabeça. Nos primeiros instantes, é vivenciado como "mortífero". Muitos acreditam que não irão "sobreviver" a ele. Fica a sensação de despedaçamento. O pediatra Aguiar (2000) esclarece que, no momento do diagnóstico, o médico também pode estar em crise. Também é difícil para o médico transmitir o diagnóstico mas é preciso entender o problema do ponto de vista dos pais. Leva-se o tempo de uma gestação para uma família conseguir processar a perda, o luto do bebê que foi sonhado, e elaborar o "nascimento" psíquico de um filho "anormal". Os nove meses de uma gestação correspondem ao timing que a natureza criou não apenas para se conceber uma criança no interior do útero, mas também junto à mãe, ao pai, aos irmãos e demais familiares que a esperam. É razoável que a "gestação" psíquica de um filho portador de deficiência, demore pelo menos mais 9 meses para ser processada (Aguiar, 2000).

A palavra enigma salta aos olhos. Parece indicar que lidar com a "anormalidade" é algo obscuro, misterioso, difícil de decifrar, difícil de compreender. Os estoques de conhecimento da família não dão conta dessa situação. O psiquiatra Camargo (2000) diz que a família, quando descobre a deficiência, vivencia como se tivesse comprado um pacote de viagem para ir a um lugar e acabasse chegando em outro lugar, inteiramente diferente. Um lugar que fala outra língua. Por essa razão, serão necessários anos e anos para se aprender a lidar com tudo isso. Aprender uma nova língua e num novo lugar nos leva a pensar na necessidade, que a "anormalidade" impõe, do grupo familiar construir um repertório social inteiramente novo, um novo habitus (Bourdieu, 1982). Essa situação requer uma adaptação afetiva e o aprendizado de regras de convivência que favoreçam a autonomia, a comu- 
nicação, a socialização e a ocupação do portador de deficiência, entre outras coisas (Assumpção Jr. \& Sprovieri, 2000).

A rotina familiar sofre abrupta mudança assinala outra mãe, ao descrever o impacto inicial com seu bebê que apresentou sérias dificuldades (diagnóstico de autismo): a gente já não tinha nem condição de dormir (...) já não tinha tempo um para o outro (...) a gente se olhava e se estranhava. A família inicialmente se ressente de tamanha interferência. Um corte se impôs na rotina do casal, perturbando sua vida íntima. O dia-a-dia alterado deixava um rastro de estranhamento. O clima era de espanto, surpresa, perplexidade e dava a impressão de perda de familiaridade. A vida a dois estava diferente. Algo fora do comum acontecia. Um já não reconhecia mais o outro, o que trazia grande desconforto, assinalado como a coisa ficou feia.

Nas narrativas das famílias, observam-se diferenças de gênero nas formas de adaptação, como pode ser visto na descrição a seguir. A mãe havia acabado de se formar e tinha expectativas de fazer um mestrado, investir profissionalmente em si. O nascimento do filho "anormal" levou-a a optar por fazer uma renúncia de si, de seus sonhos, em prol dos cuidados com o filho. Tomou para si o ônus de acompanhar cotidianamente o filho, inclusive abrindo mão de deixá-lo com a avó materna ou com uma empregada, o que seria possivelmente uma opção a seu alcance, em seu padrão de vida de classe média : a bananosa tem que ficar na minha mão mesmo. Há uma idéia de assumir a dor, o sacrifício instaurador, como se fosse uma espécie de martírio aceito pela integridade interior de seu papel de mãe, por uma boa maternagem, em benefício da família como um todo. A bananosa é a situação de alguém que se embananou, ou seja, que se envolveu com sérias dificuldades. Aqui, se refere às complicações do filho que a mãe toma para si, com quem se apresenta para ser imolada, assumindo uma ética da responsabilidade. A visão que compartilha de si, de seu martírio, é de quem está atada a limites rígidos que lhe impedem de ter uma vida "normal". O pai, como militar, manteve seu papel de provedor do lar, cooperando na divisão do tempo com o filho mas reivindicando a garantia de seu espaço, sobretudo quando traz um trabalho importante para terminar em casa. Ele nutre o gosto pela leitura e quer usufruir momentos de maior interioridade. A mãe, por sua vez, es- tá atenta em prover os espaços individualizados do pai.

Há descontinuidades e desencontro na fala deste próximo casal. Diferentes impressões se chocam: o pai conta que o médico decidiu estourar a bolsa e induzir o parto. A mãe acha que o bebê foi aspirado. O pai diz que foi retirado a fórceps. Ele acha que foi erro médico, no entanto, diz que esta suspeita não pode ser confirma$d a$. No contexto de enunciação dessa entrevista notei que o casal discordava na maioria dos pontos. O clima era tenso. Fiquei com a impressão de que havia uma profunda cisão, marcada por desencontros e diferenças na visão de mundo, no modo como o casal se apresentava. Para se compreender esta narrativa, será preciso fazer uma descrição densa, recorrendo à memória dos elos de gerações.

O marido teve uma infância muito pobre. Sofreu uma séria ruptura familiar entre os parentes de sua família materna e paterna, aos sete anos de idade, que culminou com a saída dele e de seus pais da fazenda onde moravam, para uma vida de extrema pobreza. Só foi conhecer luz elétrica aos 16 anos. Aprendeu a admirar seu próprio pai, ágil carpinteiro e a desmerecer sua mãe, descrita como uma pamonha, de temperamento parado, professora que não exercia a profissão. A idéia de família para ele tem a marca de um profundo desgosto. Ele ascendeu socialmente e se tornou engenheiro, superando o próprio pai. No entanto, ainda hoje se sente como um bicho do mato. A esposa e seus irmãos sofreram abuso físico de seu próprio pai, na infância. Apanhava de cinto, de fio, era colocada trancada em quarto escuro. Em casa havia fila das crianças para apanhar. Ela não podia comer fora de hora, o banho era regulado, para ver TV era preciso implorar. Seus pais, apesar do ambiente conflitivo em que viviam, só se separaram quando ela já tinha 22 anos, o que trouxe melhora para o relacionamento familiar. Sua mãe era uma pessoa boa, religiosa, trabalhadora, ajudava os filhos a cumprir os deveres da escola. A esposa retém de semelhante à sogra a profissão de professora e, se diferencia dela, por exercer efetivamente a profissão.

O início do casamento deste casal é relatado por eles como sendo muito bom. Depois foram surgindo as brigas, contam. Acham-se completamente diferentes. A esposa é perfeccionista e o marido é prático. As diferenças se acentuaram com o tempo. O marido não queria ter filhos, a esposa estava ambivalente a es- 
se respeito. Então, uma gravidez pouco desejada, após quatro anos de casamento, tornou-se um evento marcado pela ruptura de sentido, ruptura de consenso, pelo imprevisto. A lembrança do parto deixou um efeito nebuloso, turvo, sem propósito. Num ponto o casal concordou: o problema todo é que nosso filho nasceu antes da hora. Com uma gravidez não planejada, um parto difícil, nasce um bebê fora de hora que traz, como contraponto, um acúmulo de anormalidades. Na história da esposa, a chegada de um filho com problemas parece adicionar mais decepções a uma vivência da existência já marcada pela dor que potencializa as marcas e cicatrizes de sua história pregressa de sofrimento. Foi o que abstraí de sua narrativa, quando disse: tenho que me retalhar muito para poder lidar com meu filho, portador de deficiência mental.

$\mathrm{Na}$ história do marido, o filho "anormal" materializa motivos para discriminação, rejeição, reativando ressentimentos arcaicos de sua infância, potencializando o reviver de uma possível ruptura familiar já vivenciada. Para ele, família é uma fonte de ameaça: dentes que podem morder a nossa bunda. No senso comum se costuma usar a expressão "chute na bunda". Ele usou, ao invés disso, o verbo morder, a imagem de um ataque que machuca, que fere, que pode até arrancar pedaço. Por outro lado, ele valoriza quando seu filho é gostado, como possivelmente desejaria ter sido gostado na infância, ao invés de ver sua família de origem expulsa, rejeitada, despedaçada, desmantelada. A presença de um filho "anormal" numa família já marcada por cicatrizes da vida parece ter potencializado vulnerabilidades pessoais de cada um, deixando um rastro desagregador.

O que chama a atenção na próxima família é o efeito de fratria. Tanto a esposa quanto o marido ocupam o lugar do primeiro filho, em sua própria fratria. Eles estavam casados há quatro anos quando decidiram ficar grávidos. Uma gravidez ótima, muito desejada, que daria lugar ao primeiro neto, primeiro filho, primeiro sobrinho, primeiro tudo. Depois de sedimentar uma vida a dois, o casal estava ávido por responder socialmente àquilo que é esperado de um jovem casal: gerar filhos sadios. Eles estavam aguardando o seu primogênito, aquele a quem era reservado o lugar do primeiro tudo. A família que nascia nessa união transcendia a visão de família que o pai retinha de sua infância e adolescência: só fui saber o que é família depois que conheci a fami- lia de minha esposa. O casal estava vivendo o momento de adquirir seus próprios filhos, ampliar a família, um momento intensamente sonhado e desejado. O parto transcorreu bem. Os primeiros problemas começaram a aparecer aos nove meses. Com um ano e meio o bebê recebeu o diagnóstico de autismo, acompanhado do seguinte enunciado: autismo não tem cura e nem tratamento. Um grande choque fazia seus sonhos ruírem: aí nessa hora deu um nó na cabeça. Uma crise se instala, uma perturbação, uma passagem muito dolorosa.

A esposa tem lembranças traumáticas da convivência com seu pai. Ele era violento, bebia demais e jogava. Originário da Croácia, havia fugido de um campo de concentração, logo após o final da guerra. Quando ela tinha dez anos, seus pais se separaram. Foi uma separação difícil. O pai chegou a ameaçar a mãe com revólver. Os contatos com o pai, após a separação, foram penosos, até que ela não quis mais ver o pai. A mãe refez sua vida, casando-se com um homem de descendência italiana. O padastro foi reconhecido como pai e seus parentes integrados na família. Ele manteve uma convivência familiar muito alegre, criando no âmbito do lar, um clima de humor saudável. Sua mãe era uma pessoa muito dura, muito pau-pau, pedra-pedra. Segundo ela, não gostava de falsidade mas fazia o que podia para lhe agradar.

O marido veio de uma família disfuncional onde havia muita briga. O pai bebia muito e era agressivo com ele. Castigava-o com correia, chinelo e cabo de vassoura. Considerava-se um saco de pancadas. Seus pais nunca chegaram a se separar. Ao construir sua própria família e conhecer a família da esposa, viu com entusiasmo a perspectiva de entrar para a família dela e conhecer um ambiente de maior harmonia.

A notícia do diagnóstico de seu primeiro filho instaurou grande perplexidade no casal. Autismo não tem cura e nem tratamento foi o enunciado que pai e mãe registraram na memória. A fala do médico fotografava a idéia de uma doença incurável, portanto a perspectiva de que a doença seria para toda a vida. Esse enunciado comum na fala médica vem de um olhar que só vê a doença e só se limita a falar dela. Ora, a criança não é a doença. A criança é um sujeito onde a doença se manifesta. Dizer que autismo não tem cura e nem tratamento produz a impressão de que não há nada a fazer nem com a doença, nem com a 
criança. Ignora a idéia da plasticidade do organismo humano que, ao se adaptar às doenças, pode gerar novas formas de vida (Canguilhem, 1990). Tal como foi dito, a informação soa como uma "sentença de morte" por duas razões. Primeiro, porque deixa de fora as capacidades auto-organizadoras da vida, da criança e da família: os tratamentos existem. Segundo, porque produz no sentimento dos pais, uma idéia de perda fatal, quando em seu imaginário a criança ainda era "normal", sem lhes dar qualquer possibilidade de vislumbrar uma saída. E assim, numa relação de choque, a família percebe nova condição no ser da criança. Essa circunstância produz um segundo nascimento, o nascimento social de uma criança "anormal", que se dá de forma negativa, estática e preconceituosa.

O momento de se informar o diagnóstico é muitíssimo importante e altamente delicado. Ele instaura um rito de passagem (Geertz, 1997) que produz simbolicamente a morte da criança idealizada e faz nascer uma nova criança, a ser concebida no imaginário dos pais. Essa segunda "gestação" exige tempo, um tempo psíquico de pelo menos outra gestação. Uma atitude profissional correta não deveria ser a de transmitir a notícia com indiferença. Pelo contrário, o médico deveria dar suporte emocional aos pais, orientá-los sobre a doença e o tratamento, ajudar no discernimento das decisões a serem tomadas no acompanhamento futuro da criança e no apoio à família. Deveria favorecer o luto e a elaboração do nascimento de uma nova vida.

Depois de ouvir o diagnóstico sobre autismo, o casal disse: nessa hora deu um nó na cabeça. Foi difícil pôr a cabeça para processar tanta dor. Deu um nó na cabeça. Foi difícil pensar, foi difícil aceitar a doença, foi difícil discernir que tipo de tratamento poderia ser feito. Inspirada em sua mãe, que via a vida pela ótica do pau-pau, pedra-pedra, a esposa não se rendeu tão facilmente à sentença dada. Não deixou por menos o desafio de enfrentar a doença. Iria negá-la duramente até que a doença lhe provasse o contrário.Tirou o filho de um dos seus primeiros tratamentos, feito com equipe multiprofissional, e por dez meses tentou ajudá-lo com as próprias mãos, recebendo instruções mensais para treiná-lo em nível psicomotor. Ao final, confirma ela, estava estafada! Exausta! Não vencera a doença. Seria necessário render-se a ela. Por mais que se esforçasse, não conseguiria recuperar seu filho. Es- te é um dos exemplos de como uma mãe concebeu em seu psiquismo o nascimento do filho "anormal". Por dez meses lutou contra a enfermidade, e nessa luta foi conhecendo o "novo" filho, a doença e seus próprios limites. Nesse embate nascia uma nova mãe e um novo pai. Mais de um luto estava sendo processado. O luto do filho idealizado, o luto da mãe idealizada e o luto do pai idealizado. Dali pra frente, o casal passou a filtrar melhor as informações e aprendeu a discernir critérios para escolha dos tratamentos que considerava mais eficazes para seu filho. O nó foi se desatando na cabeça e na prática. A dor foi encarada, o que parece ter propiciado melhores condições para sua elaboração. Um segundo filho saudável nasceu alguns anos depois. A família cresceu e continua cuidando do desenvolvimento de ambos os filhos, o mais velho com seis anos e um bebê de dez meses. O casal ainda hoje é "flagrado" apaixonado. Marido e mulher não abriram mão de se "curtir" e investir na família. Esse filho "anormal”, ao contrário do caso anterior, produziu um efeito agregador na família. A dor é um convite à transformação. Quando bem-elaborada, fortalece a família, vivifica os laços familiares, favorece um melhor desenvolvimento da criança "anormal".

Vejamos como outra mãe descreve as crianças "anormais", tendo como base a experiência com seu filho, portador de psicose infantil. Essas próprias crianças assim com esses problemas são um livro difícil de você tentar ler, entendeu? Você vê de uma forma as figuras, mas a escrita é totalmente diferente, é como se estivesse mostrando uma violência (...) aquela mágoa toda. A escrita é totalmente uma poesia (...) Aquilo ali não tem nada a ver com o que está escrito... Aquele negócio que você vê assim, as aparências enganam... Você está vendo a pessoa de um jeito e aquela pessoa é totalmente diferente daquilo ali. Salta-me aos olhos, inicialmente, a palavra 'violência', palavra complexa e polissêmica. A imagem de uma criança "anormal" é marcada por uma violação de regras de conduta e expectativas sociais. Uma violação que pode afetar a integração física, moral, mental ou espiritual; que se mostra como agressividade e produz conflito social; que altera os mecanismos de adaptação psíquica e psicobiológica; que produz insatisfação e confrontação, e gera a necessidade de reconstrução de sentimentos e emoções (Minayo \& Souza, 1998). O filho "anormal", que inspirou esse enunciado, encontrava-se numa fase muito difícil, com 
condutas altamente desorganizadas e agressivas. Posteriormente, teve grande progresso em seu tratamento e sua adaptação psicossocial melhorou sensivelmente. Mas esse período crítico e desagregador foi vivenciado pela mãe como um enigma difícil de decifrar. Diz ela, você vê uma figura, um rosto, uma face, um corpo, uma expressão, mas a escrita é totalmente diferente. O sentido dos gestos, das falas, dos atos, dos hábitos, das emoções é totalmente diferente daquilo que se imagina, é algo inesperado, é um vocabulário estranho, desconhecido. Esse enunciado produz um efeito de sentido cheio de descontinuidades, de fraturas do pensamento frente a um real que se mostra desalinhado e às avessas. O tom emocional é de mágoa, de ressentimento, de algo que machuca e fere. A escrita é uma poesia ao mesmo tempo em que nada tem a ver com o que está escrito. $\mathrm{O}$ que fica retido dessa escrita é a perda de sentido, a ruptura com a significação e a perplexidade. As aparências enganam, você vê a pessoa de um jeito e aquela pessoa é totalmente diferente. A pessoa diferente confunde, engana, choca, violenta. Aprender a traduzir esse vocabulário estranho, essa língua tão diferente é um imenso desafio. Com o passar do tempo e o tratamento da criança, a dor tende a se amenizar no momento em que se pode melhor compreender e conhecer a criança, quando se sente que é possível aprender a lidar com ela no dia-a-dia, quando se descobre que a própria criança tem muito a nos ensinar a seu respeito.

Vejamos, então, outro depoimento: Tem algo de desequilibrado na cabeça dele, descontinuidade. Ele tem ótima memória visual. Fala muito explicado. Um pouco de descontrole nas pernas. Muita firmeza nas mãos, é muito agitado e irrequieto. Quando entra em crise, se morde, chora. Sono muito agitado. Medo de som, sirene! Não se interessa por brinquedos. Leva tudo à boca. Repete as coisas. Não usa o pronome 'eu'. Diz sempre 'você', 'seu'. O diagnóstico ainda não está fechado. Há suspeita de autismo. Em poucas palavras, essa mãe consegue descrever os sinais da anormalidade de seu filho, em seus próprios termos, demonstrando familiaridade com o jargão Psi. Quando diz há algo desequilibrado na cabeça dele, parece estar implícita uma pergunta: o que há de desequilibrado na cabeça dele? Ela descreve os efeitos desse desequilíbrio na memória, na fala, nas pernas, nas mãos, no comportamento, ao dormir, ao sentir certas emoções. Toma, como base, um certo estatuto de pessoa "normal" e relaciona os elementos que se aproximam e se afastam dele, assinalando aonde as coisas vão bem e aonde não vão: a memória visual é ótima, boa firmeza nas mãos (...) sono agitado, medo de sirene (...). Ora, é justamente esse estatuto de pessoa que está em jogo, um ideal de pessoa "equilibrada".

O que é doença em uma cultura, pode não ser em outra. O que é sofrimento em um contexto, pode não ser em outro. Mas em nossa sociedade ocidental, o mandato social da "normalidade" mantém uma rédea, mais ou menos rígida, sobre os parâmetros de construção de pessoas esperadas. E isso está tão entranhado em nosso imaginário social porque nele se projeta uma outra face dessa moeda submersa no mundo interno. Vejamos uma narrativa extraída de uma sessão de psicoterapia de família: temos a sensação de possuirmos ferramentas defeituosas que fabricam bebês defeituosos (...) Eu me surpreendo com o fato do meu filho ser igual a todo mundo por fora e tão diferente por dentro (...) Meu bebê antes era normal. Tinha problemas que podiam ser melhorados com o tempo. Depois o bebê virou um bebê monstro - ele engana, ele parece que é bonito mas não é, eu sinto como se ele fosse um bebê monstro. Ter a sensação de possuir ferramentas "defeituosas" que produzem bebês "defeituosos" representa a outra face da moeda, quando a cultura entranha no sujeito todo um simbolismo de normalidade e rejeita o diferente e o desigual. Mais que isso, num universo individualista, o sujeito toma para si a causa e a origem da anormalidade. Uma mãe que produz um bebê "defeituoso" é uma mãe que se sente com um interior alterado, com um útero "anômalo". Uma mãe que gera um bebê "monstro" é uma mãe que também se sente "monstruosa”. Um bebê que não é o que parece, é um bebê que engana, assusta, horroriza pois revela uma face "monstruosa" da natureza humana.

Se o sentimento de um interior "defeituoso" vem a ser uma das faces da moeda, de um simbolismo que se encarna num indivíduo concreto, interiorizado, com um grau de reflexividade de si mesmo expandida, então como poderíamos ver a outra face dessa mesma moeda, na dimensão da sociedade? Essa outra narrativa nos dá uma pista nessa direção: Só que as dores que a gente sente mesmo, as dores que ... na selva de pedra... quer dizer que é a cidade, que é a rua, quando a gente sai de dentro 
de nossa casa. Por mais humilde que seja, dentro de nossa casa ... qualquer coisa que um filho da gente fizer a gente consegue suportar e contornar a situação, né? (...) mas quando saem na rua ... as pessoas não querem nem saber... a rua é uma selva de pedra, as pessoas estão querendo sempre uma atropelar a outra (...) Por mais que a gente tenha amor, tenha fraternidade, a gente não agüenta, a gente fica sobrecarregado (...) então fica difícil, sabe, muito difícil... E as pessoas perguntam: Por que que ele é assim? Por que que ele está fazendo isso? Por que ele está fazendo aquilo? E eu nunca sei esse porquê... responder a esse porquê... Eu também faço essas perguntas... O sofrimento instaurador aqui não é percebido no interior do sujeito, mas no interior da sociedade. Esta representada como 'a selva de pedra', a rua, o lugar em que as pessoas estão querendo atropelar umas às outras, um lugar onde as pessoas se olham mas não se vêem, se encontram mas não se reconhecem. O lugar do trânsito, dos muitos rostos despersonalizados, perdidos na multidão, da pressa, do corre-corre. O lugar onde as diferenças ganham visibilidade, são notadas, são anunciadas e denunciadas: "Por que que ele é assim? Por que que ele está fazendo aquilo?" Aqui a mãe não olha para seu interior. No entanto, ela também enxerga defeitos - os defeitos dos recursos de que dispõe para lidar com os desafios de seu filho nesse mundo de exigências selvagens: por mais que a gente tenha amor, tenha fraternidade, a gente não agüenta, a gente fica sobrecarregado. A vivência de fracasso é aqui sentida na interação social, do mesmo modo que a "mãe-monstro" se sentia fracassando naquilo que concebeu em seu interior. Por outro lado, tanto o "bebê-monstro" como o "menino-selvagem" da selva-de-pedra ganham visibilidade, notoriedade, por sua diferença, "monstruosidade" ou "selvageria", a depender do nosso ponto de vista. Se parece monstruoso por dentro, ou selvagem por fora, são duas faces de uma mesma moeda.

A consciência de um $e u$ que olha a si, numa reflexividade, ou a consciência do olhar do outro sobre esse $e u$, em circunstâncias de anormalidade, parece ter que assumir a força de uma intensa desmistificação: como demonstrar que não se trata de um monstro, nem de um selvagem? A idéia de "besta endemoniada" que pairava sobre os "deficientes", na época da inquisição, parece persistir ainda hoje, como um fantasma a assombrar os processos de subjetivação da maternagem e paternagem recém-construídos. Quando os muros da vida privada se ergueram, no princípio do século XIX, a criança ganhou uma importância afetiva outrora desconhecida. Intimidade e identidade passaram a ser marcas da família moderna. Desde então, tudo o que ocorre com a criança passa a atingir a família (Ariès, 1978).

A dor, experimentada por uma mãe no lidar cotidiano com a anormalidade, é posta em palavras nesta narrativa: os pais dessas crianças ("anormais") acabam virando um bicho de sete cabeças e se tornando uma pessoa mais insuportável do que os filhos (...) Eu estava contribuindo para deixar ele pior, eu estava agindo errado demais com ele. (...) Se a gente não se cura dessa doença de dentro da gente primeiro (...) que machuca muito... por dentro (...) pra depois tentar curar essa daí de fora, a gente pi$r a$. Aqui nós temos um dentro e um fora, e uma dor que precisa ser gerenciada internamente, na consciência de si e externamente na interação com o outro.

Lá, de dentro do mundo interno, sai um bicho de sete cabeças. Anuncia um combate, um confronto, um grande perigo. Momento oportuno para se recorrer ao mito de Hércules (Brandão, 1989). Como a Hidra de Lerna, serpente descomunal de sete cabeças, o monstro interior se ergue do pântano da dor, da perplexidade, da falta de entendimento e apavora. Seu hálito pestilento é altamente destruidor como as palavras que saem desnorteadas e confusas, causando estrago. Quando cortada, cada cabeça renasce e se duplica, como as angústias que se multiplicam e atormentam cada vez mais. Enquanto o monstro vive, as cabeças renascem, assim como a desorientação produz e reproduz um desespero insuportável. O desafio é gigantesco. Com espada e fogo, Hércules mata e cauteriza cada cabeça, levando a serpente à morte. Como o herói mitológico, é preciso enfrentar a dor e acabar com aquilo que machuca e fere por dentro e por fora. Com a espada da determinação é preciso persistir na busca de ajuda, até encontrá-la. Só curando e cauterizando as feridas o monstro é vencido, o combate é bem-sucedido.

Não se deve subestimar a complexidade da perturbação que afeta as famílias, a potência e amplitude da dor. O desafio é hercúleo. As angústias podem ser avassaladoras e catastróficas devendo, por isso, ser seriamente consideradas e cuidadas. É de suma importância o apoio à família, para que tenha melhores condições de dar suporte aos filhos. Como diz 
Winnicott (1982), a criança é uma organização em marcha e o mundo precisa ser apresentado em pequenas doses. É preciso conhecer cada criança "anormal" para descobrir um modo, que mais lhe atenda, de lhe ensinar o mundo. É preciso muita tolerância para se entender que as respostas dessas crianças também virão em pequenas doses. Vejamos como uma avó se gratifica com seu neto, portador de autismo, nas pequeninas conquistas cotidianas:

São pouquinhas coisas que ele aprendeu mas essas pouquinhas coisas, pra mim, são muito importantes. Outro dia eu estava dando banho nele, o sabonete caiu aí eu: "Pega F."(neto)! Mas esqueci de falar "o sabonete". Aí ele falou: "saboete". Então isso é uma coisinha muito pequena para quem está ouvindo, mas pra mim isto é imenso, sabe!

\section{Conclusão}

A etnografia das narrativas familiares, como se pôde ver, enfocou sobretudo as etapas iniciais pelas quais a família passa quando descobre a anormalidade de seu filho. Pretendeu mostrar a densidade da experiência da família num momento tão difícil de sua vida. A fotografia de algumas falas e a descrição de seu contexto enunciativo me permitiram explorar a riqueza com que as famílias vivenciam esse desafio, sob o seu próprio ponto de vista.

O momento do diagnóstico é delicadíssimo. As palavras que serão ditas terão efeito performativo, ou seja, irão se transformar em ato. $\mathrm{O}$ ato de dizer que aquela criança possui uma deficiência na hora do diagnóstico irá transformar a criança "normal" numa criança "anormal". Irá instaurar um rito de passagem, muitíssimo doloroso, que requer tempo para ser processado: tempo para se recuperar de um corte irreversível; tempo para se conceber uma nova criança no psiquismo da família; tempo para se descobrir o que é ser pai e mãe de uma criança com anormalidades mentais tão precoces. A revelação do diagnóstico não pode ficar restrita apenas a uma fala informativa, indiferente de quem fala em relação a quem escuta. Ela precisa ser feita a partir de uma compreensão global da família e das dificuldades intrínsecas a esse momento. As reações à dor serão inevitáveis. O acolhimento, o apoio, uma orientação clara serão fundamentais. É preciso mostrar quais são as alternativas e possibilidades de ajuda à criança e à família.

A rotina familiar se altera, alguém na família passará a ser mais exigido. Alguém, dali pra frente, terá que se dedicar mais à criança, dentro da família. Geralmente a mãe assume a "bananosa", por sua expectativa em prover uma boa maternagem, em benefício de toda a família. Outras pessoas podem vir a assumir, ou a repartir esse "ônus", a depender dos valores, do contexto social e do significado que a família constrói para o filho "anormal". Dali pra frente vai haver muito o que aprender, muito o que entender, muito a se avaliar. Inúmeras perguntas vão surgir, muitas respostas só virão com o tempo, com a experiência cotidiana. Muita angústia, muita dor, muita perplexidade terão que ser enfrentadas, na via crucis da busca de ajuda. Os vários especialistas e as diferentes opiniões trarão a pesada angústia da decisão. Como decidir, quando ainda é tão difícil entender a complexidade do que está por vir? Como decidir, sem entender direito alguns especialistas, pouco preocupados em traduzir em palavras simples o problema da criança, impacientes ao explicar, tão indispostos a ouvir?

Será preciso desenvolver um novo estoque de conhecimento na família. A quem recorrer? Por um lado, temos a herança das gerações precedentes, com suas lições de vida, as histórias de suas dores, explicitadas ou guardadas em segredo. Nessas histórias ou mitos familiares (Prado, 1999) iremos encontrar ferramentais psíquicos, valores, modelos de identificação que poderão nos auxiliar ou não. As cicatrizes do passado podem nos fragilizar ou nos fortalecer. Depende do que eu consegui fazer do que fizeram de mim (Sartre, 1980). Por outro lado, temos a sociedade, com suas alternativas. Pode-se recorrer a elas e/ou tentar inventar novas soluções, quando vários pais se organizam por uma causa social comum.

Não se pode subestimar a importância do apoio que deve ser dado à família. Este ponto é crucial. O desafio é hercúleo. A desorientação, a confusão, o desespero podem produzir "bichos de sete cabeças". É preciso dominar esses monstros, e também aqueles que ainda estão entranhados no imaginário social. Ao invés de ver nestas crianças diferentes "monstros" ou "selvagens", deveríamos procurar conhecê-las mais de perto, descobrir com elas a invenção de seu mundo e reinventarmos o nosso mundo, para que elas se tornem persona- 
gens de nossas vidas. Este olhar estranho é resultante de um olhar social, avesso às diferenças, que acaba sendo reencontrado no interior daqueles que sofrem o seu reflexo, que ficam como espelhos dessas crianças na sociedade. Os pais reencontram dentro de si o "monstro" ou o "selvagem" quando recebem, na pele, toda a carga da discriminação social. O que se precisa dominar e combater com veemência é a serpente da discriminação. Esta sim, é perigosa e deixa um rastro de destruição por onde passa.

\section{Referências bibliográficas}

Aguiar MJB 2000. O profissional e a família. Curso para compreender a deficiência, Salgado MI \& Valadares ER (orgs.). Promovido pelo Centro de Extensão da Faculdade de Medicina da UFMG.

Ajuriaguerra J 1980. As psicoses infantis, pp. 665-722. Manual de psiquiatria infantil. Ed. Masson do Brasil, Rio de Janeiro.

AMA/SP 2000. Você sabe o que é o autismo? Revista dos Amigos. Uma publicação da Associação de Amigos do Autista 1(1): 22-24.

Ariès P 1978. História social da criança e da família. Ed. Guanabara Koogan, Rio de Janeiro, 279 pp.

Assumpção Jr. FB \& Sprovieri MH 2000. Introdução ao estudo da deficiência mental. Memnon, São Paulo, $164 \mathrm{pp}$.

Bakhtin H 1979. Marxismo e filosofia da linguagem. Problemas fundamentais do método sociológico na ciência da linguagem. Ed. Hucitec, São Paulo, 182 pp.

Basso, EB 1990. Native Latin American cultures through their discurse. Indiana University Press, Bloomington, $175 \mathrm{pp}$.

Benveniste E 1974. Problèmes de linguistique gènèrale. Gallimard, Paris, 413 pp.

Bourdieu P 1982. Les rites comme actes d'instituition. Actes de la recherche en sciences Sociales: juin; 58-63.

Bourdieu P 1996. A ilusão biográfica, pp. 181-191.In Ferreira MM \& Amado J (orgs.). Usos e abusos da história oral. Ed. Fundação Getúlio Vargas, Rio de Janeiro.

Brandão JS 1989. Mitologia grega. Vol. I, III. Ed. Vozes, Petrópolis.

Camargo Jr.W 2000. Deficiência e educação (coord.). Curso para compreender a deficiência, Salgado MI \& Valadares ER (orgs.). Promovido pelo Centro de Extensão da Faculdade de Medicina da UFMG.

Canguilhem G 1990. O normal e o patológico. Ed. Forense Universitária, Rio de Janeiro, 307 pp.

Cavalcante FG 1996. A gramática da criança "anormal" na narrativa familiar. Um estudo etnográfico. Dissertação de mestrado. Programa de Pós-Graduação em psicologia e práticas socioculturais da UERJ, Rio de Janeiro, 246 pp.

Costa JF 1994. Pragmática e processo analítico: Freud Wittgenstein, Davidson, Rorty, pp.9-60. In JF Costa (org.). Redescrições da psicanálise: ensaios pragmáticos. Relume-Dumará, Rio de Janeiro.
DSM-IV 1995. Critérios diagnósticos. Artes Médicas, Porto Alegre, $340 \mathrm{pp}$.

Ducrot O 1987. O dizer e o dito. Ed. Pontes, Campinas, 220 pp.

Faustino S 1995. Wittgenstein, o eu e sua gramática. Editora Ática, São Paulo, 120 pp.

Foucault M 1995. As palavras e as coisas.Ed. Martins Fontes, São Paulo, 407 pp.

Gergen KJ 1994. Realities and relationships. Soundings in social construction. Harvard University Press, Cambridge, Massachusetts, e Londres, 356 pp.

Geertz C 1997. O saber local. Ed.Vozes, Petrópolis.

Geertz C 1989. A interpretação das culturas. Ed. Guanabara, Rio de Janeiro.

Lèvi-Strauss C 1990. Aula inaugural. In Guimarães AZ (org.). Francisco Alves Ed, Rio de Janeiro.

Linton R 1987. O homem: uma introdução à antropologia. Ed. Martins Fontes, São Paulo, 470 pp.

Minayo MCS \& Souza ER 1998. Violência e saúde como um campo interdisciplinar e de Ação coletiva. História, Ciências, Saúde-Manguinhos, IV(3): 513 531.

Pedro MCCA 1999. Destino e mito familiar: uma questão da família psicótica. Vetor, São Paulo, 226 pp.

Rorty R 1994. A filosofia e o espelho da linguagem. Relume-Dumará, Rio de Janeiro, 386 pp.

Santos BS 1997. Um discurso sobre as ciências. Edições Afrontamento, Porto, $57 \mathrm{pp}$.

Sartre JP 1980. Questão do método em Sartre. Os pensadores. Ed. Abril Cultural, São Paulo, 191 pp.

Schutz A 1971. Concept and theory formation in the social sciences. Sociological perspective, Peguin Books. Middlessex.

Silva MGV 2000. Acompanhamento familiar: uma proposta institucional. I Mostra de Experiências de Sucesso: trabalho com famílias. Prefeitura do Rio de Janeiro/SMDS.

Stegmüller, W. Filosofia II, pp. 430-524. A filosofia contemporânea: introdução crítica. Ed. USP, São Paulo.

Winnicott DW 1982. A criança e o seu mundo. Ed. Guanabara Koogan, Rio de Janeiro, 270 pp.

Wittgenstein L 1979. Investigações filosóficas. Ed. Abril Cultural, São Paulo, 222 pp. 